\title{
LINEAR ECONOMY VERSUS CIRCULAR ECONOMY: A COMPARATIVE AND ANALYZER STUDY FOR OPTIMIZATION OF ECONOMY FOR SUSTAINABILITY
}

\section{Furkan Sariatli}

Szent István University, Gödöllő, Hungary

\begin{abstract}
Upon visiting the existing literature on the subject of linear vs. circular economy, this paper finds that, the blueprint of the current economy is hardly sustainable by using the comparative benchmarking method that drained from literature. The intrinsic mechanics of the linear economy, by relying on the wasteful take - make - dispose flow, is detrimental to the environment, cannot supply the growing populace of our planet with essential services and it naturally leads to strained profitability. Elements of a plausible solution to the challenges have been around for decades, although they have only recently been compiled in to the conceptual framework of circular economy. The core ideas of Circular Economy are elimination of waste by design, respect for the social, economic and natural environment and resource-conscious business conduct. Built on the backbone of these principles, the circular economy has demonstrated to deliver tangible benefits and viability to address the economic, environmental and social challenges of our days.
\end{abstract}

Keywords: circular, linear, environment, failure, benefits, transition

\section{Introduction}

This paper discusses presumably the most fundamental, complex and systemic challenges of our days: the foundations, the design and the substantial principles of the economy. Hence, the circular economy implies a conception or system that keeps the added value of a product as much as possible and eliminates the waste. When a product ends its life cycle, it is supposed to be kept within the economy as resource which can be used productively again and again and thus create a further value (European Commission (2014). The work includes the research on the unsustainability of the traditional linear economy, which contains environmental, demographic and economic components. Based on the input from credible secondary sources, it will be demonstrated that the natural environment is approaching (or surpassing) a tipping point where the world irreversibly loses its capacity to sustain the biosphere as we know it. Further, it will be shown that the conventional linear economic model that has shone in the conditions of resource abundance, reaches the limit for supplying the input the mankind needs for sustenance in the empirical economic and demographic trends. The paper will present the basic principles, the composing elements and the benefits of the circular economy alternative, which promises not merely to lengthen the availability of the remaining pool of resources, but to permanently improve the efficiency of the economy and to enable prolonged supply for the growing needs of humanity.

\section{Impetus to Transition: Environmental Concerns}

Although the environmental burden of the humanity has been known to accelerate since the industrialization, by the new millennium 1.5 Planet Earths are estimated to be needed to support our social, economic and demographic existence (WWF, 2012). In an attempt to classify the human impact on the ecosystem, Rockström et al. (2009) introduced the concept of Planetary Boundaries, referring to key environmental thresholds which, when crossed, can change the current ecosystem irreversibly. In the latest publication of the group (Steffen et al., 2015), the researchers claim that four of the nine Planetary Boundaries have already been crossed: the climate has already changed, the biosphere has lost its integrity, the land-system has been altered and the biogeochemical cycles have been corrupted. The Millennium Ecosystem Assessment (2005, cited by the Ellen MacArthur Foundation (2013)), states that fifteen out of the recognized twenty-four ecosystem services (i.e. processes of nature that support human wellbeing) are used in an unsustainable manner or are being depleted. Based on these recognitions, Steffen et al. (2015) argue that the relative stability and the slowly evolving environmental conditions that were characteristic in the Holocene geological era has been surpassed by the era of Anthropocene, which is distinctive of the abrupt and dramatic deviations caused by the economic activity as well as the social and demographic burdens imposed by mankind. Although not everyone embraces the radicalness of the ideas suggested by the Planetary Boundaries, it is hardly debatable that the world's natural tolerance to human activity appears to be growing tired and the ecosystem shows signs of being worn down.

\section{The Linear Model and its Failure (strengths)}

According to the Ellen MacArthur Foundation (2013), the currently prevailing economic design has its roots in the historically uneven distribution of wealth by geographic region. As the consumers of resources have been largely concentrated on the most developed regions (i.e. in the western societies), and the material inputs have been sourced increasingly from the global arena, the industrial nations have experienced an abundance of material resources and energy. In this arrangement, the materials have been cheap compared to the cost of human labor. Resultantly, the producers have been motivated to adopt business models that relied on extensive use of materials and economized on human work. What is more: the more energy and materials they have been able to utilize to supplement human capital, the more competitive edge they could manage to gain. The natural consequence of cheap material / expensive labor is the common neglect of recycling, reusing and putting much emphasis on waste. The regulatory, accounting and fiscal rules have also been supportive of this scheme, as they did not issue a protocol to charge producers with the externalities, therefore the producers have been less encouraged to consider the external costs of their operations. In addition, the system had 
a natural lock-in inertia, as the official product approval procedures tend to favor the existing practices over radical changes and reinvention of basic principles. The upshot of this economic blueprint is the linear economy. Its essence is generally summarized as take - make - dispose. That is, take the resources you need, make the goods to be sold and make profit and dispose of everything you do not need - including a product at the end of its lifecycle.

Based on empirical data and economic modelling, the Ellen MacArthur Foundation (2013) quantifies some of the costs of the linear model. The source cites the report of the Sustainable Europe Research Institute (SERI) which claims that 21 billion tons of materials used in production do not get incorporated in the final product (i.e. they are lost during the transition between the forms of materials, in production, as unused by-products, due to inefficiency, as a result of storage problems, etc.). The Ellen MacArthur Foundation (2013) refers to Eurostat (2011) data indicating that the volume of material input to the European economy tallied with 65 billion tons in 2010 , out of which 2.7 billion tons were dumped as waste, merely 40 percent of which was used again in any form (e.g. through recycling, reusing or composting). The unmanaged waste lost not only its original function, but it was also wasted as a source of energy.

While the linear economy has been highly successful in generating material wealth in the industrial nations up to the $20^{\text {th }}$ century, it has demonstrated weaknesses in the new millennium and the ultimate breakdown in the near future is forecast. Based on data of professional sources, the Ellen MacArthur Foundation (2013) states that the commodity prices have met a tipping point in 1999 and the previously declining material costs gained a volatile upward momentum. The incremental prices and high volatility can be attributed to the increased demand that pushed the output to a point in the cost curve where incremental production costs dearly and to the depletion of easy to access extraction sites, which exposes mining to taking technological risks for bringing new sites online. This trend has been paired with increasing competition, which has prevented companies from passing the increasing prices on to their customers - eventually exerting a profit squeeze on firms and driving the value of total economic output down.

According to the Ellen MacArthur Foundation (2013), several of the current trends extrapolated further deterioration in the potential of the linear economy to the future projects. The demographic evolution of the mankind further shifts the concentration of the population from the traditionally densely populated industrialized nations towards the emerging markets. This trend, coupled with the lightning-fast economic development of China and India has been and is increasing the global mass of middle class consumers by an estimated 3 billion with corresponding consumption, which is predicted to cost 3 trillion USD per annum in infrastructural investment (Dobbs et al., 2011). According to the Ellen MacArthur Foundation (2013), failing to meet this level of investment, the economy is unavoidably growing to be supply constrained - particularly in the western economies that already operate at their near maximum capacity for example in terms of food. Addressing these questions is fundamentally challenging, even if one discounts the local and global political tensions, the growing interconnectedness of the markets through financialization and the deterioration of the environment.

\section{Conceptual Overview of Circular Economy}

Deriving from empirically tested models of environmental erosion and the systemic impact of the economy on the environment, the prevailing notion governing production and consumption more is better [...] needs to be entirely replaced by 'positive development in which markets work to automatically, systematically make things better both locally and globally (Greyson, 2016). Conceptualized by environment-conscious economists, the conventional linear economy (described by the widely-cited line of take make - dispose) is to be supplanted by the circular economy.

The phrase circular economy (CE) itself was introduced by Pearce and Turner (1989), although the concept has deep roots dating back to the 1960s and it has been contributed by a large number of researchers, theorists and vocational parties. As the Ellen MacArthur Foundation (2015a) puts it, the circular economy should be considered a framework: as a generic notion, the circular economy draws on several more specific approaches that gravitate around a set of basic principles (Ellen MacArthur Foundation, 2015a). To comprehend the concept, it is due to establish the composing ideas. The relevance of this approach is underscored by the fact that pan-national organizations (such as the World Economic Forum, 2016) also signed to and adopted the interdisciplinary composition of circular economy.

The dawn of CE can be traced back to Boulding (1966), who suggested to implement a cyclical ecological system instead of the wasteful linear economic model. While the cyclical economic scheme of Boulding (1966) was rather fluid, it spurred further conceptual development of sustainability. Stahel (1982) introduced the notion of spiral-loop (or closed loop) selfreplenishing economic construct, which Stahel (2010) eventually developed to the idea of "performance" economy. The essence of the performance economy is the redefinition of the subject of production, sales and maintenance: instead of goods, firms should market performance, as for example in the recently surging sharing based business models. The concept of Stahl was incorporated in the successful cradle-to-cradle initiative of Braungart and McDonough (2008), which considers all material involved in industrial and commercial processes to be nutrients, of which there are two main categories: technical and biological (Ellen MacArthur Foundation, 2015b). A further aspect and building block of the circular economy is biomimicry. Proposed by Benyus (1998), the economic system is to mimic (as in learn from and imitate) the ways of nature to cope with industrial and commercial challenges and gauge operational efficiency against solutions experienced in the nature. The circular economy also takes advantage of the scientific approach of the industrial ecology, which is concerned with the energy and material flow of the industrial (and other economic) systems, aiming to create closed loop processes that minimize waste by deploying interdisciplinary scientific methodology and by regarding both the local and the global natural and social environments (Ellen Macarthur Foundation, 2015c). The notion of natural capitalism aims to create a shared economic platform that recognizes the needs of both the environment and the capital. The core propositions of natural capitalism are: creating closed-loop production cycle to reuse nondegradable materials; elevating the efficiency of resource usage to lengthen the availability of natural resources; redefining the producer - user contract to "service and flow" model rather than "sell and use" and quantifying the value of natural resources to promote reinvestment in nature (Hawken et al., 1999). The blue economy concept extends the ideas regarding waste-usage; beyond internal closed-loop production cycles, the waste of one industry should be regarded as a potential input to different sectors, whose arrangement is often dubbed as cascading (Pauli, 2009).

\section{Benefits of Circular Economy}

The more an industrial foundation reuses and cycles its waste, the closer it approaches to the idea of circular economy and to being more profitable (Lancaster, 2002) while also less harmless for environment. CE mainly promotes virgin material minimization and espousal of clean technologies (Andersen 1997, 1999). In industrial environment, it is intended to show that circular economy would be beneficial for society. Benefits will be taken not only using environment as a reservoir for residual wastes but restricting 
or minimizing the usage of exhausting material for production activities. The expected benefits are focused on the basic monitoring that the loss of material wastes, in countable units, is minimized (Andersen, 2007).

To expand, there are vital points made by the Ellen MacArthur Foundation (2013), based on modelling the application of the principles of the circular economy, a long range of tangible benefits can be detected first of all that deploy circular design in technological product categories (for example via standardization, modularization or via embedding disassembly concerns in product design) and result in securing access to better and cheaper materials. Furthermore, performance based (e.g. sharing) business models have already proved their dollar worth in a number of sectors. In that sense, Proficiency in the reverse material flow cycle is a potential competitive edge for businesses while CE also opens up employment opportunities, developing expertise in legal, mechanical, operational or cross-sectoral challenges. The methods of circular economy are highly scalable; therefore, CE is capable to fuel growth and attract investment capital. Thus, incorporating the attributes of $C E$ in the $R \& D$ phase of operation yields spurs progress in material sciences and yields the development of higher quality and more durable components.

The elimination of waste from the value chain has the quantifiable benefit of reducing systemic and direct material cost and diminishing resource dependence. Thus, circular economy benefits organizations with operational as well as strategic advantages. It means that, by reducing the level of material input needed, the economy may save billions of dollars. The transition/advance scenario estimates of the Ellen MacArthur Foundation (2013) say the European Union may save up to 400/600 billion USD in material costs annually, primarily in the automotive and machinery sectors. From this point of view, due to the closed-loop processes, the economy grows less exposed to price fluctuations of the materials and the flattened cost curve ultimately results in a more efficient use of resources in terms of both value and volume.

As a result of that, the sectoral composition of the economy shifts towards the more innovative, efficient and productive service sector, as the majority of externalities is associated with the use and flow of material, lower material consumption evidently decreases the exposure to externalities and the growing efficiency of material use stimulates innovation and yields creative solutions beyond the immediate cost related benefits

Last but not least, there are outcomes reflecting to end users such as the reverse flow of materials extending the consumer - producer contact, benefiting firms with elevated consumer loyalty, product designs with reuse of materials incorporated reduce complexity and prolong product life-cycles which will make product consumer-benefit centered, application of the principles of the circular economy promotes production of goods built-to-last, which ultimately reduces the total cost of ownership and the market receives new ways of accessing goods (e.g. through sharing), which enriches the set of choices and increases customer satisfaction. Controversially, although practicing those above, there are still obstacles we have to cope with such as in Chinese example; deficiency of social indicators, lack of indicators for industrial/urban reconciliation, lack of indicators of business performance, lack of prevention oriented indicators, lack of measurable criteria and certain barriers on implementation (Geng et al., 2011).

\section{SWOT Analysis for Circular Economy versus Linear Economy}

Although there are quite enormous benefits and opportunities of circular economy, it is also necessary to cope with a series of hardships. Circular economy implies a more manageable waste, recyclable resources, profitable organizations and more sustainable environment, however, awareness of it is still arguable and tendency upon Circular economy by sectoral and governmental still is quite minimal level. A set of legal, $R \& D$, capital and introductory rules and campaigns yet needs to be done. As described below, it is intended to indicate some certain values which may assist us to scale current and future standing implicated by the SWOT analysis.

\section{Strengths:}

$\square$ Proficiency in the reverse material flow cycle is a potential competitive edge.

$\square$ Elimination of waste from the value chain has the quantifiable benefit of reducing systemic and direct material cost and diminishing resource dependence.

$\square$ Incorporating the attributes of $C E$ in the $R \& D$ phase of operation yields spurs progress in material sciences and yields the development of higher quality and more durable components.

$\square$ Due to the closed-loop processes, the economy grows less exposed to price fluctuations of the materials and the flattened cost curve ultimately results in more efficient use of resources in terms of both value and volume.

$\square$ Externalities are associated with the use and flow of material, lower material consumption evidently decreases the exposure to externalities.

\section{Weaknesses:}

$\square$ Circular economy still requires amalgamation of the entire product life cycle from raw material provision to annihilation (Van Ewijik, 2014).

$\square$ No specific guidelines to sectors on how to implement circular economy.

$\square$ There is still no internationally recognized standards institution to regulate the sector (Circular Academy, 2017).

$\square$ Circular Economy may omit the feature of semi-recyclability when choosing a raw material for production process.

$\square$ Public opinion about CE is yet inefficient and social marketing campaigns lack to access sectoral people.

$\square$ There is still no special legal regulation about circular economy and its application (Circular Academy, 2017).

$\square$ Investments about circular economy to introduce the system to sector are not enough.

\section{Opportunities:}

$\square$ By reducing the level of material input needed, the economy may save billions of dollars. The EU may save up to 600 billion USD in material costs annually.

$\square$ Deploying circular design in technological products, results in securing access to better and cheaper materials.

$\square$ Developing expertise in legal, mechanical, operational or cross-sectoral challenges in circular solutions opens business opportunity for the enablers.

$\square$ Developing expertise in sectoral or cross-sectoral challenges in circular solutions opens business opportunity for the enablers.

\section{Threts}

$\square$ If companies can control entire life cycle, they can easily cross-subsidize different activities and that can cause high prices and incapable products.

$\square$ If producers could direct their own product-waste, it may be more difficult to benefit from waste management for those in scale economy.

$\square$ Managing whole life cycle of product and strong collaboration can cause cartel structures. 
$\square$ A gradual or sequencing financial disruptions in the system can cause unpleasant outcomes for the interdependant sector due to complex and interlinked sector (Van Ewijik, 2014).

\section{Conclusion}

The paper observed the fundamental challenges of the current economic arrangements: the linear economy. It was established that the take - make dispose construct is not suited to meet the current, let alone the projected future needs of mankind. The investigation found that the economic agents throughout the prevalence of the linear economy have been intrinsically counter-motivated to be mindful for resource exploitation efficiency, which resulted in excessive level of waste output. The recent environmental and economic trends have palpably demonstrated that the blueprint of the linear economy has met its limits: on the one hand, the natural environment seems to be unable to tolerate the current level of resource exploitation; on the other hand, the growing scarcity of resources driven both by the depletion and by increasing demand due to the demographic trends exerts relentless pressure on the attainable profit.

The paper found that the circular economy is a viable, sustainable and unavoidable alternative which is capable to cope with the challenges. The collection of concepts composing the circular economy enables reducing the waste by incorporating reusing components of goods by design via closed loop and cascaded approaches, containing the dependence of the economy on material and energy inputs, increasing the resilience of the economic system, the preservation of the environment, supplying the growing demands of the ever more populated planet and increasing the operationability and costefficiency of production. What is more, the circular economy is compatible with the inherent interests of the corporations, as it is aligned with the competitive and the strategic frameworks and it is capable to enrich the contract between the consumers and the producers.

Ultimately, the author personally finds the transition from the linear to the circular economy essential. The author particularly finds it valuable that although it requires fundamental alterations of the mechanics of production and consumption, it is down to earth in terms of human needs and it does not impose unrealistic expectations from any segment of the value chain or from the consumers.

\section{References}

ANDERSEN, MS. 1997. Evaluation of the cleaner technology programme, environmental review no. 14. Environmental Protection Agency, Copenhagen. [Online]. Retrieved on April 19,2017 Availableat:http://pure.au.dk//portal/files/86521632/deanertechn_uk.pdf

ANDERSEN, MS. 1999. Governance by green taxes: implementing clean water policies in Europe 1970-1990. In Environmental Economy Policy Studies, vol. 2, no. 1, pp. 39-63. [Online]. Retrieved on April 19, 2017. Available at: http://pure.au.dk/portal/ files/12075926/Andersen_Governance_by_green_taxes.pdf

ANDERSEN, MS. 2006. An introductory note on the environmental economics of the circular economy, Springer, pp. 133-134 [0nline]. Retrieved on April 19, 2017. Available at: https://yale.instructure.com/files/252409/download?download_frd=1\&verifier=8v leVX171ry2C2k9GwktMuei2Vs1tjnH1on6VFSS

BENYUS, J. 1998. Biomimicry: innovation inspired by nature. New York : Quill, 1998.

BOULDING, K. 1966. The economics of the coming spaceship Earth. In Jarrett, H. (ed) Environmental quality in a growing economy. Baltimore : Johns Hopkins University Press, 1966.

BRAUNGART, M. - McDONOUGH, W. 2008. Cradle-to-cradle - Remaking the way we make things. New York : North Point Press, 2008.

CIRCULAR ACADEMY. 2017. Circular economy: critics and challenges - How can we bridge the circularity gap? [Online]. Retrieved on February 21, 2017. Available at: http:// www.circular.academy/circular-economy-critics-and-challenges/
DOBBS, R. - OPPENHEIMER, J. - THOMPSON, F. - BRINKMAN, M. - ZORNES, M. 2011. Resource revolution: Meeting the world's energy, material, food, and water needs. [Online]. Accessed on Dec 21, 2016. Available at: http://www.mckinsey.com/ business-functions/sustainability-and-resource-productivity/our-insights/resourcerevolution

ELLEN MacARTHUR FOUNDATION. 2013. Towards the circular economy. [Online]. Accessed on Dec 21, 2016. Available at: https://www.ellenmacarthurfoundation.org/assets/ downloads/publications/Ellen-MacArthur-Foundation-Towards-the-CircularEconomy-vol.1.pdf

ELLEN MacARTHUR FOUNDATION. 2015a. Schools of thought - performance economy. [0nline]. Accessed on Dec 21, 2016. Available at: https://www. ellenmacarthurfoundation.org/circular-economy/schools-of-thought/performanceeconomy

ELLEN MacARTHUR FOUNDATION. 2015b. Schools of thought-industrial ecology. [Online]. Accessed on Dec 21, 2016. Available at: https://www.ellenmacarthurfoundation.org/ circular-economy/schools-of-thought/cradle2cradle

ELLEN MacARTHUR FOUNDATION. 2015c. Schools of thought - cradle to cradle. [Online]. Accessed on Dec 21, 2016. Available at: https://www.ellenmacarthurfoundation.org/ circular-economy/schools-of-thought/industrial-ecology

EUROPEAN COMISSION. 2014. Towards a circular economy: A zero waste programme for Europe. Brussels, pp. 2, 2.7.2014 COM 398 final. [Online]. Retrieved on Feb 10 2017. Available at: http://ec.europa.eu/environment/circular-economy/pdf/circulareconomy-communication.pdf

EUROSTAT. 2011. Waste statistics. [0nline]. Accessed on Dec 21, 2016. Available at: http:// ec.europa.eu/eurostat/statistics-explained/index.php/Waste_statistics

GENGA, Y. - FUA, J. - SARKISC J. - XUEA, B. 2012. Towards a national circular economy indicator system in China: an evaluation and critical analysis. In Journal of Cleaner Production, vol. 23, 2012, no. 1, pp. 216-224.

GREYSON, J. 2016. A glance at waste-free economy. [Online]. Available at: http://www. ecomena.org/tag/linear-economy/

HAWKEN, P. - LOVINS, A.B. - LOVINS, L.H. 1999. Natural capitalism: The next industrial evolution. London : Earthscan, 1999.

PAULI, G. 2009. 10 years 100 innovations 100 million jobs inspired by nature. Report to the Club of Rome. [Online]. Accessed on Dec 21, 2016. Available at: http://www. worldacademy.org/files/Blue\%20Economy\%202009.pdf

PEARCE, D.W. - TURNER, R.K. 1989. Economics of natural resources and the environment. Baltimore: Johns Hopkins University Press, 1989.

ROCKSTRÖM, J. - STEFFEN, W. - NOONE, K. - PERSSON, et al. 2009. A safe operating space for humanity. In Nature, vol. 461, 2009, no. 24, pp. 472-475.

STAHEL, W. 1982. Product-life factor. [Online]. Accessed on Dec 21, 2016. Available at: http://www.product-life.org/en/major-publications/the-product-life-factor

STAHEL, W. 2010. The performance economy $2^{\text {nd }}$ ed. Basingstoke: Palgrave MacMillan, 2010.

STEFFEN, W. - RICHARDSON, K. - ROCKSTRÖM, J. - CORNELL, et al. 2015. Planetary boundaries: Guiding human development on a changing planet. In Science, 347 (6223), 2015.

VAN EWJIK, STIJIN. 2014. Three Challenges to the Circular Economy, UCL Institute for Sustainable Resources. [0nline]. Retrieved on February 26, 2017. Available at: https://blogs.ucl.ac.uk/sustainable-resources/2014/03/10/three-challenges-to-thecircular-economy/

WORLD ECONOMIC FORUM. 2016. From linear to circular - Accelerating a proven concept. [Online]. Accessed on Dec 21, 2016. Available at: http://reports.weforum.org/towardthe-circular-economy-accelerating-the-scale-up-across-global-supply-chains/fromlinear-to-circular-accelerating-a-proven-concept/

WWF. 2012. Living planet report 2012 - Biodiversity, biocapacity and better choices. [Online]. Retrieved on Dec 21, 2016. Available at: http://www.worldwildlife.org/ publications/living-planet-report-2012-biodiversity-biocapacity-and-better-choices

\section{Contact address}

Furkan Sariatli, PhD Student, Szent Istvan University, Faculty of Economics and Social Sciences, Doctoral School for MBA, Pater Karoly ut.1, 2100 Gödöllö, Hungary, e-mail: fsariatli@anadolu.edu.tr 